\title{
alphauille
}

\section{Far East Film Festival 20}

\section{Boel Ulfsdotter and Mats Björkin}

After running successfully for twenty years, the Far East Film Festival (FEFF) in Udine, Italy, has become established as the most important overseas festival devoted to East Asian popular cinema. The Hong Kong Film Festival remains one of its main sources ever since the Centro Espressioni Cinematografiche of Udine began to display an interest in East Asian cinema by organising its first programme of Hong Kong films in 1998. Another key source of inspiration for FEFF is the Busan Film Festival in South Korea, from which FEFF takes both recently released and restored popular films.

Having experienced almost all editions of FEFF during the past two decades, we have been able to observe that the festival has been motivated by a strong wish to grow its Western audience's knowledge of East Asian cinema. For many years it has screened a number of historical films accompanied by scholarly and critical publications which today are considered important resources for those interested in the cinema from this region. As regular members of its audience we have been fortunate to have had the opportunity to see numerous rare films; among the most memorable series were the Hong Kong Stories: The TV Works of Ann Hui (2009); Asia Sings (2006), on the modern East Asian musical genre; Asia Laughs (2011), on East Asian comedies; No Borders, No Limits: The World of Nikkatsu Action (2005); and Nudes! Guns! Ghosts! - The Sensational World of Shintoho (2010).

In terms of film productions released within the previous eighteen months, and thus eligible for screening in competition in Udine, the festival has remained focused on a number of areas, namely the performance of the South Korean film industry, the rapid expansion of China's mainland market, developments in Taiwan and the transformation of the Hong Kong film industry. FEFF has also picked up the best film fare produced by the neighbouring Southeast Asian industries, ranging from the small film industry of Singapore to the large and mature film industry of Thailand. For many years, the festival has also showcased films from the Philippines, a quite unique tradition mixing local storytelling with Hollywood and Hong Kong genres and styles.

The main ideology of the festival - to screen films that are popular in East Asia rather than regular festival (arthouse) vehicles - is still prevailing. In terms of its historiography, one of the more unexpected developments in East Asian popular cinema, for instance, is demonstrated in the fact that the festival now screens more films from Mainland China than from Hong Kong. The main reason for this development is Mainland China's open ambition to produce as many successful popular films as Hong Kong's industry. Huge budgets, and potentially large audiences, have attracted filmmakers from Hong Kong to make films in China. They certainly cannot tell the same stories, but they bring their unique style and precious production skills. In return, the Hong Kong industry may refrain from offering innovative stories; thus, the two film industries risk a gradual alignment. Over the years, the festival's programmes have reflected the fascinating development of the South Korean cinema, from its 
days of "Cinemania" to the considerable crisis which reached its peak around 2007, until its return to the top around 2012. The festival has consistently avoided both the arthouse and anime film fare from Japan, while opting to tell the story of a film industry with long traditions of well-crafted and well-acted genre films. Finally, over the past twenty years, we have been able to follow the growth of Taiwan's commercial film industry beyond the highly visible arthouse successes reflecting a basically Eurocentric perspective.

From an industrial point of view, however, it is difficult to tell whether FEFF has succeeded in convincing the European markets to distribute and screen more films from East Asia. After many years of ambitious DVD releases in Italy and with the growing streaming markets in Europe, FEFF has certainly contributed to an increasing interest in East Asian films in Europe. FEFF's potential impact principally relies on the film students, scholars, critics and festival organisers who have attended screenings, met directors, actors and producers during the festival talks. In addition to this, new festivals specialising in East Asian cinema are emerging all over Europe. Notable examples are the London Korean Film Festival and Nippon Connection in Frankfurt, Germany. Finally, European universities are recording an increasing demand and offer of East Asian cinema courses (from the BA in Film Studies and East Asian Studies at the University of Manchester to the Cinéma asiatique/Cinémas d'Asie module at Paris 3 Sorbonne Nouvelle and the Chinese Cinemas course at King's College London).

As for the twentieth edition of FEFF, held on 20-28 April 2018, it is our contention that it perfectly reflected the dominating trends of the East Asian film industries in terms of output by presenting South Korea as the most prolific and inventive industry in the region. South Korea has contributed the largest number of films to FEFF during the past decade. This development highlights the lack of new and original stories from China, despite its high output, while the number of films from Hong Kong sadly continues to decrease, with the country now being only the third largest contributor of films to the festival. At the same time, the huge Mainland market makes big production budgets possible, thus representing a serious alternative for many Hong Kong filmmakers, despite their being heavily state controlled. The upside is, therefore, a chance at well-crafted genre films that feed off the traditional Hong Kong film industry and its genres. The downside is films that keep safe margins to China's firm censorship laws, which limit the production environment in Mainland China, and indirectly make Hong Kong's industry prone to self-censorship. The result is a mix of high-concept and empty stories. Enter the Hong Kong film industry which, in spite of its increasingly circumscribed production conditions, manages to fearlessly reinvent its traditional genres. The most impressive attempt this year was Chapman To's The Empty Hands (Hung sau dou, 2017), a story about karate fighting and a father-daughter relationship gone awry, told from a female perspective. Given the karate film's traditional narrative being veered towards a male audience, this is indeed an unexpected turn of events. It was hardly surprising that the European premiere of To's film was very favourably received by the audience and critics at the festival. The annual screening of "Fresh Wave" projects from Hong Kong's film schools this year offered three impressive shorts, reflecting perfect mastery of difficult tropes like stream-of-consciousness narration, the little girl's perspective, and restricted cinematography - the latter no doubt paying tribute to Christopher Doyle's expertly executed rendition of the island's traditionally cramped spaces in In the Mood for Love (Faa yeung nin wa, Wong Kar-wai, 2000).

We also conclude that Hong Kong filmmakers after the Umbrella Movement of the 2014 Hong Kong democracy protests seem to have become more anxious, while other directors have become more politically engaged. In 2016, FEFF screened the dystopic Ten Years (Sahp Nihn, Peter Chan and Catherine Chau, 2015), an omnibus film presenting fearful forecasts of 
Hong Kong under Mainland rule in 2025. This year, Derek Chiu presented his No. 1 Chung Ying Street (Chung Ying Gai Yat Hou, 2018), a film as yet without regular distribution. It is a brave and daring project mirroring the 1967 Maoist uprising against the British colonial rule which develops into a story set in the near future (2019), with an unnamed Chinese rule over Hong Kong. Shot in black and white, the film took eight years to complete and displays some nonfiction footage from 1967 added to the fictional storyline. Discreetly, but probably more than obvious for the Hong Kong audience, drawings of umbrellas as well as photos from the Umbrella Movement make it clear that the film moves beyond the old British-Chinese dichotomy, towards the dream of a free, democratic Hong Kong, whatever the formal rule. Veteran Ann Hui's Hong Kong-China coproduction Our Time Will Come (Ming yue ji shi you, 2017 ) is set during the Japanese occupation of Hong Kong in the 1930s. The narrative revolves around a young woman who gets involved with a resistance group helping dissidents to escape to unoccupied neighbouring territories. Had it not been for the heroes' use of umbrellas to avoid being discovered by Japanese soldiers the film could have been read simply as a historical drama, with the extra value of including a female resistance leader. An alternative reading of the mise en scène, as well as its everyday realism, the umbrellas, and the locale, however, turn the film into a political allegory, which, if needed, still remains fully reversible.

The political theme is also present in some of the South Korean films screened at FEFF20. Gwon Gyung-won's documentary Courtesy to the Nation (Gukga-e daehan ye-ui, 2017) follows the case of a student activist who was framed for instigating a suicide wave among student and worker activists in 1991. The brutal military rule of South Korea has often been recreated for the big screen over the past ten years, but it seems that the filmmakers now leave the 1960s and 1970s atrocities behind and focus on the later years of the (semi)military regime. Other films use the corruption of the political and legal systems as well as of the press to visually capture thriller and crime stories. Since South Korea's abolishment of screen censorship in the early 1990s, this type of films is being produced to critical praise and financial success, especially in terms of Korea's young cinema audiences that have an increasing interest in contemporary and recent historical events. Contemporary politics are also foregrounded in Raya Martin's Smaller and Smaller Circles (2017), about two Jesuit priests and a television journalist investigating a series of murders while both the Church and the political establishment try to prevent them from exposing child abuse by a priest. In the festival catalogue, film critic Phan Xi Nê pinpoints that the other major trend in the region, that of female-oriented narratives, applies to the Vietnamese film industry as well in 2017. This year's programme in Udine provided a wonderful example of this trend with first-time directors Kay Nguyên and Trân Buu Lôc's The Tailor (Co Ba Sai Gon, 2017), whose plot centres on a fashion designer living in the 1960s who time-travels to modern day Saigon to learn a lesson about traditional dress.

Taiwanese actress Brigitte Lin Ching Hsia received the Mulberry Life Time Award this year, and the festival honoured her outstanding film career in East Asia by screening six of her films. The series was curated by Shi Nan-Sun, one of Hong Kong's top film producers, best known in the West for her work as a jury member of the Cannes Film Festival. The Lin series was originally compiled for the Hong Kong Film Fest, which explains the inclusion of Wong Kar-wai's Chungking Express (Chung Hing sam lam, 1994). In addition to this rare arthouse production in Lin's filmography, Shi selected two films from her early career in Taiwan: her debut Outside the Window (Chuang wai, Sung Tsun-Shou and Yok Teng-heung, 1974), an accomplished tale of forbidden love between a teacher and his pupil, based on a popular novel. The film not only initiated a series of romantic melodramas from Taiwan, but also instigated an intense debate regarding the country's incrimination of this particular type of love affair. 
The other early melodrama starring Lin was Cloud of Romance (Wo shi yi pian yun, Chen Hung-lieh, 1977), which made even higher demands on the then young and untrained actress. Given the deeply patriarchal and misogynist culture in East Asia at the time, it is perhaps needless to point out that it is Lin's leading female character who pays the price in both films. Having been asked who helped her picking suitable roles in the early years of her career, Lin answered that only her mother was at hand. At the time, none of the film industries in either Taiwan or Hong Kong provided their top-billed stars with agents or producers who could advise them on which career moves would best be made. During her years in the Hong Kong film industry in the 1980s and 1990s, Lin also starred in Yim Ho's dreamy Red Dust (Gun gun hong chen, 1990) with newcomer Maggie Chung, as well as in several wuxia or sword-fighting films. It is therefore deeply satisfying to see that, during her last two years before retiring, Lin again changed genres and teamed up with Wong Kar-wai in Chungking Express and Ashes of Time (Dung che sai duk, 1994).

The choice of a female personality as the recipient of this year's Golden Mulberry Life Time Award is of course partly related to the \#MeToo movement. In fact, showcasing works by women seems to have been a leading ambition of this year's edition of the festival. Apart from the presence of works by important professionals such as Brigitte Lin Ching Hsia and Ann Hui, three films deserve to be mentioned here. Taiwan-born Sylvia Chang is one of the region's most renowned professionals, with her over one hundred screen performances and fourteen films made as a director. She contributed to this year's programme in Udine with her Love Education (Xiang ai xiang qin, 2017), based on her own script, in which she plays a woman trying to reunite her parents in a common grave. The film is an updated representative of the "ethnological" trend first introduced by Mainland China's fifth generation directors. In terms of production, her Korean junior Moon So-ri repeats Chang's strategy in The Running Actress (Yeo-bae-u-neun O-neul-do, 2017), which is characterised by a strong narrative refinement. This is a revealing, deeply self-reflexive film about the travails of a mature, successful actress working for the Korean industry. It is told from an everyday perspective. Moon's unguarded acting is striking for its frankness and lack of glamour, features that produce the unexpected effect of unveiling a film star persona. A third contribution worth mentioning is Yim Soon-rye's unusual coming-of-age Little Forest (Liteul poreseuteu, 2018). Labelled as a "bittersweet foody drama" in the film programme and based on a manga tale, Little Forest tells the story of a young woman who failed in her first attempt to start up a professional career in the city. Returning to her countryside home, she mulls over her future between cooking, gardening and helping out with the harvest in her home village. Despite the huffing comments of many veterans in the business, Yim's film has become a great success with the young Korean audiences on account of its realism and ambition to reconnect with basic life values. Needless to say, the versatile and attentive productions by these two Korean directors alone seem to indicate that a lasting change in attitude towards female authorship may well come from South Korea. Our contention is backed by the fact that its industry so far seems to be the only one open to the influence of the \#MeToo movement in East Asia. The versatility and continuously strong performance of this particular industry is also indicated by the fact that the newly introduced White Mulberry Award for first- or second-time directors was awarded to the South Korean (male) director Shin Dong-seok for his strong drama Last Child (2018).

In summing up, programmers Sabrina Baracetti and Thomas Bertacche have succeded in establishing the Far East Film Festival as a unique player not only among European film festivals, but as a festival of East Asian cinema. In view of their plans to extend the festival's scope by including successful East Asian TV-drama productions in its programme, FEFF will stay ahead of its Western contenders when it comes to screen productions from this part of the 
world. As a transnational screening window, FEFF seems set to continue to look at the East Asian film industries from both a global market perspective (the festival management and audience) and an insider critical perspective (their local consultants) without ever becoming a distant observer.

\section{References}

Ashes of Time [Dung che sai duk]. Directed by Wong Kar-wai, Jet Tone Productions, 1994.

Chungking Express [Chung Hing sam lam]. Directed by Wong Kar-wai, Jet Tone Productions, 1994.

Cloud of Romance [Wo shi yi pian yun] Directed by Chen Hung-lieh, Super Star (H.K.) Motion Picture Company, 1977.

Courtesy to the Nation [Gukga-e daehan ye-ui]. Directed by Gwon Gyung-won, 2017.

The Empty Hands [Hung sau dou]. Directed by Chapman To, HK Film Production, 2017.

Garcia, Roger. Asia Sings! A Survey of Asian Musical Films. Centro Espressioni Cinematografiche, 2006.

---. Asia Laughs! A Survey of Asian Comedy Films. Centro Espressioni Cinematografiche, 2011.

In the Mood for Love [Faa yeung nin wa]. Directed by Wong Kar-wai, Jet Tone Productions, 2000.

Last Child [Saranam-eun ai]. Directed by Shin Dong-seok, Finecut, 2018.

Little Forest [Liteul poreseuteu]. Directed by Yim Soon-rye, Watermelon Pictures Co., 2018.

Love Education [Xiang ai xiang qin]. Directed by Sylvia Chang, Beijing Hairun Pictures Company, 2017.

No. 1 Chung Ying Street [Chung Ying Gai Yat Hou]. Directed by Derek Chiu, Boundary Film Production, 2018.

Our Time Will Come [Ming yue ji shi you]. Directed by Ann Hui, Shanghai Bona Cultural Media, 2017.

Outside the Window [Chuang wai]. Directed by Sung Tsun-Shou and Yok Teng-heung, Eighty Years of Film Company, 1974.

Red Dust [Gun gun hong chen]. Directed by Yim Ho, Hong Kong Pineast Pictures, 1990.

The Running Actress [Yeo-bae-u-neun O-neul-do]. Directed by Moon So-ri, Jenna Ku, 2017. 
Schilling, Mark. No Borders, No Limits: The World of Nikkatsu Action. Centro Espressioni Cinematografiche, 2005.

---. Nudes! Guns! Ghosts! The Sensational Films of Shintoho. Centro Espressioni Cinematografiche, 2010.

Smaller and Smaller Circles. Directed by Raya Martin, TBA Studios, 2017.

The Tailor [Co Ba Sai Gon]. Directed by Kay Nguyên and Trân Buu Lôc, VAA, 2017.

Ten Years [Sahp Nihn]. Directed by Peter Chan and Catherine Chau, Ten Years Studio, 2015.

Youngs, Tim. Hong Kong Stories: The TV Works of Ann Hui. Centro Espressioni Cinematografiche, 2009.

\section{Suggested Citation}

Ulfsdotter, Boel, and Mats Björkin. "Far East Film Festival 20." Festival Report. Alphaville: Journal of Film and Screen Media, no. 15, Summer 2018, pp. 168-173. www.alphavillejournal.com/Issue15/ReportUlfsdotterBjörkin.pdf.

Boel Ulfsdotter is an independent media scholar, guest lecturer, and visual culture critic, affiliated with the University of Gothenburg, Sweden.

Mats Björkin is Associate Professor of Film Studies at the University of Gothenburg, Sweden. 